\title{
CC Chemokine Receptor 4 Contributes to Innate NK and Chronic Stage T Helper Cell Recall Responses during Mycobacterium bovis Infection
}

\author{
Valerie R. Stolberg, ${ }^{*}$ Bo-Chin Chiu, ${ }^{\dagger}$ \\ Brian M. Schmidt, ${ }^{*}$ Steven L. Kunkel, ${ }^{\dagger}$ \\ Matyas Sandor, ${ }^{\ddagger}$ and Stephen W. Chensue ${ }^{\star \dagger}$ \\ From the Department of Pathology and Laboratory Medicine," VA \\ Ann Arbor Healthcare System, Ann Arbor, Michigan; the \\ Department of Pathology, University of Michigan Medical School, \\ Ann Arbor, Michigan; and the Department of Pathology and \\ Laboratory Medicine, ${ }^{\ddagger}$ University of Wisconsin, Madison, Wisconsin.
}

Cysteine-cysteinyl chemokine receptor 4 (CCR4) is expressed by a variety of T-cell subsets and leukocytes. This study examined the participation of CCR4 in response to pulmonary infection with Mycobacterium bovis BacilleCalmette-Guerin (BCG). Constitutive and induced CCR4 agonist expression was detected among large mononuclear cells. The course of infection and mobilization of effector cell populations were then analyzed in CCR4 knockout $\left(\mathrm{CCR}^{-1-}\right)$ mice. Compared with controls, $\mathrm{CCR} 4^{-1-}$ mice displayed delayed innate stage $(<2$ weeks) bacterial clearance and reduced late stage inflammation. Innate impairment was associated with reduced natural killer cell activation. In the adaptive phase, $\mathrm{CCR} 4^{-1-}$ mice generated effector $T$ cells in draining lymph nodes and accumulated effector $T$ cells in lungs, which resulted in normal adaptive stage bacterial elimination at 2 to 4 weeks. However, during the late stage, $\mathrm{CCR}^{-1-}$ mice had reduced interferon $\gamma+\mathrm{CD}^{+} \alpha / \beta+$ (Th1) and interleukin (II)$17+\mathrm{CD}^{+} \alpha / \beta+(\mathrm{Th} 17) \mathrm{T}$ helper cells in lungs. In contrast, $\mathrm{IL}-17+\gamma / \delta$ T cells in lungs were unaffected. When challenged with mycobacterial antigen- (Ag-) Ag-coated beads to elicit a recall granulomatous response, CCR4 $4^{-/-}$mice displayed abrogated recall granuloma formation and reduced interferon $\gamma+$ Th1 cells. These findings indicate that $\mathrm{CCR} 4$ supports innate natural killer cell activation and sustains later $\mathrm{CD} 4^{+}$Th effector/memory antimycobacterial responses in the lung but is redundant in the early adaptive elimination phase. (Am J Pathol 2011, 178:233-244; DOI: 10.1016/j.ajpath.2010.11.036)

The CC chemokine receptor 4 (CCR4) is widely expressed among leukocyte populations. In addition to T-cell subsets,
CCR4 is reportedly expressed by platelets, natural killer (NK) cells, macrophages, basophils, and dendritic cells (DCs). ${ }^{1}$ Regarding T-cell subsets, naïve T cells do not express CCR4, suggesting a role in memory or effector T-cell function. Initially, CCR4 was purported to be a marker of Th2 cells, but mounting evidence suggests that this is not the case. The CCR4 genetic deletion had no effect in a mouse model of Th2-dependent ovalbumin (OVA)-elicited allergy airway response. ${ }^{2}$ We demonstrated that CCR4+ Th1 and Th2 cells were detected in mouse models of Th1 and Th2 cell-mediated pulmonary granulomatous inflammation, respectively, elicited by mycobacterial and helminth antigens. ${ }^{3}$ In a detailed analysis ${ }^{4}$ of human peripheral blood T cells, CCR4 expression was detected on isolated human $\mathrm{CD}^{+}{ }^{+}$memory $\mathrm{T}$ cells with Th1 and Th2 characteristics. The specific ligands for CCR4, cysteine-cysteinyl ligan (CCL)17, and CCL22 induced migration of both Th1 and Th2 cells in vitro. $^{5,6}$ In addition, CCR4 is reportedly expressed by human CD4+CD25+ T-regulatory cells and Th17 cells. ${ }^{7,8}$ Other studies ${ }^{9-11}$ suggest that CCR4 confers T cells the specific capacity to migrate to skin. However, CCR4 appears to participate in modulation of lung and liver granulomatous inflammations and the innate response to peritoneal bacterial sepsis. ${ }^{12,13}$ In view of its expression among varied leukocyte populations, CCR4 is likely involved in multiple aspects of both innate and adaptive immunity.

The requirement for CCR4 in mounting a maximal Th1 response to mycobacterial antigens using experimental models of pulmonary granulomas elicited by challenge with bead-immobilized mycobacterial antigens was recently reported. ${ }^{3}$ This finding was unexpected and provided further evidence that CCR4 expression and function were not restricted to Th2 cells. However, the role of CCR4 in the lung response to a live mycobacterial agent was unknown. In the

Supported by NIH-National Institute of Allergy and Infectious Diseases (grant A143460) and in part by the Department of Veterans Affairs and NIH (grants HL92845, HL31963, and HL89216).

Accepted for publication September 30, 2010.

Supplementary material for this article can be found at $h$ ttp://ajp.amjpathol.org, and at DOI:10.1016/j.ajpath.2010.11.036

Address reprint requests to Stephen W. Chensue, M.D., Ph.D., Pathology and Laboratory Medicine 113, VA Ann Arbor Healthcare System 2215 Fuller Rd, Ann Arbor, Ml 48105. E-mail: schensue@med.umich.edu. 
present study, we further investigated CCR4 contribution to the antimycobacterial response in a model of live Mycobacterium bovis infection. By using CCR4 knockout mice, our study examined multiple parameters of the immune response after pulmonary exposure to mycobacteria. These included innate resistance, induction of effector cells in draining lymphoid tissues, mobilization of effector cells to infected lungs, and ability to mount a recall inflammatory response to mycobacterial antigens. The results show effects on the innate NK cell response and adaptive Th1 and Th17 memory responses, with complete sparing of $\gamma / \delta$ Tcell responses. The CCR4 appeared to be required for sustaining the local pulmonary memory effector response in the long-term but not early bacterial elimination stage of infection. Therefore, CCR4 may play a central role in homeostatic and late-stage organ-based effector responses. The findings have important implications for antimycobacterial vaccine design and treatment of chronic inflammation.

\section{Materials and Methods}

\section{Animals}

Mice lacking the CCR4 gene (CCR4 ${ }^{-l-}$ ) were provided by Tularik Inc., (South San Francisco, CA) were generated as previously described, ${ }^{2}$ and were bred onto a C57BL/6 background. Knockout status was confirmed by RT-PCR analysis using gene-specific primers and probes. The C57BL/6 wild-type (WT) mice were obtained from Jackson Laboratory, Bar Harbor, ME. CD90.1 (B6.PL-Thy $1<\mathrm{a}>/ \mathrm{CyJ}$ ) C57BL/6 congenic and C57BL/6$\mathrm{Tg}($ TcraTcrb) $425 \mathrm{Cbn} / \mathrm{J} \mathrm{T}$ cell receptor (TCR) ovalbumin transgenic (OT-II) mice were purchased from Jackson Laboratory. The $\mathrm{CD}^{+} \mathrm{T}$ cells from the OT-II mice are specific for OVA peptide of amino acids 323-339 (EKLTEWTSSNVMEER) in the context of major histocompatibility complex antigen. ${ }^{26}$ The OT-II TCR transgenic mice expressing CD90.1 on a C57BL/6 background were bred in house using male OT-II and female B6.PL-Thy1a/ CyJ mice. All mice were maintained under specific pathogen-free conditions and provided with food and water ad libitum in an Association for Assessment and Accreditation of Laboratory Animal Care (AAALAC) approved facility. All animal studies were approved by an institutional review board.

\section{M. bovis BCG Strains and Colony-Forming Unit Determinations}

M. bovis BCG, Pasteur strain (Trudeau Institute, Saranac Lake, NY), was propagated in liquid 7H9 medium supplemented with $0.5 \%$ glycerol, $10 \%$ oleic acid-albumindextrose catalase and $0.05 \%$ polysorbate detergent (Tween 80). Organisms were harvested in mid-log growth stage, usually 16 to 20 days of culture at $37^{\circ}$ in a humidified 6\% carbon dioxide atmosphere. Aliquoted BCG was stored at $-80^{\circ}$ in PBS-glycerol (1:1). Preparations were washed with PBS before in vivo administration.

Recombinant BCG-OVA was prepared using a construct containing the green fluorescent protein gene driven by a mycobacterial heat shock protein 60 promoter and carrying a kanamycin resistance gene, which was provided by Glenn Fennelly (Albert Einstein Yeshiva University, New York, NY), as previously described. ${ }^{14}$ Ovalbumin peptides recognized by the OT-I and OT-II TCR-transgenic T cells were cloned by PCR into the C-terminal end of the GFP molecule using extended primers. The altered construct was checked by sequencing, then BCG-Pasteur was transfected with the OVA peptide construct and selected in kanamycin-containing media. The transfected BCGs were GFP positive, and in in vitro splenic cultures both OT-I and OT-II cells were activated by the recombinant bacteria or bacterial lysates. The production of peptides was also confirmed by Western blotting. The course of BCG infection and the bacterial load determined by colony-forming units (CFUs) were similar in C57BL/6 mice infected with the WT or the recombinant GFP-OVA-BCG.

Colony-forming units were determined by counting numbers of colonies developing from serial dilutions distributed on Middlebrook 7H10 agar (100-mm) plates with oleic acid-albumin-dextrose catalase supplement. Plates were cultured at $37^{\circ}$ in a humidified $6 \%$ carbon dioxide atmosphere for 2 to 3 weeks. For lung CFUs, whole lungs were homogenized in $20 \mathrm{ml}$ of sterile PBS using a Waring blender. Tissue slurries were pelleted by centrifugation and resuspended in $2 \mathrm{ml}$ of sterile water, and serial dilutions were applied to Middlebrook agar described for colony counting.

\section{M. bovis BCG Infection}

Mice were exposed to 1 million M. bovis BCG CFUs i.t. Briefly, mice were subjected to ketamine or xylazine anesthesia and then secured by soft restraint to an operating board to expose the neck. After iodine field disinfection, a 5- to 6-mm midline incision was made to expose the trachea. By using a 26-gauge needle and syringe, $1 \times 10^{6}$ organisms in a $0.025-\mathrm{ml}$ volume were injected in the tracheal lumen, followed by closure of the skin wound with a 4-0 suture (Softsilk) on a C-13 cutting needle. For recovery, mice were placed on a water-jacketed heating pad to maintain body temperature.

\section{Induction of Synchronized Anamnestic Granulomas}

Secondary type $1 \mathrm{Ag}$-bead granulomas were generated as previously described. ${ }^{15}$ Briefly, BCG-infected mice were challenged i.v. with 6000 beads (Sepharose 4B) covalently coupled to $M$. bovis-purified protein derivative (PPD) (Department of Agriculture, Veterinary Division, Ames, IA). For histological analysis, individual excised lung lobes were inflated and fixed with 10\% buffered formalin for morphometric analysis. The granuloma area was measured in a blinded fashion in hematoxylin-eosinstained sections of paraffin-embedded lungs using computer-assisted morphometry. A minimum of 20 lesions was measured per lung. 


\section{Lymph Node Cell Isolation and Culture}

After perfusion with cold RPMI 1640 medium (Sigma Aldrich, St Louis, MO), lungs, excluding trachea and major bronchi, and mediastinal lymph nodes were excised. Lymph nodes were teased into a single-cell suspension and then cultured in RPMI 1640-supplemented medium (RPMI 1640 medium with 20-mmol/L HEPES buffer, 10\% fetal bovine serum, $100-U$ penicillin, and $100-\mu \mathrm{g} / \mathrm{ml}$ streptomycin) at $5 \times 10^{6}$ cells $/ \mathrm{ml}$ in the presence or absence of $10-\mu \mathrm{g} / \mathrm{ml}$ PPD. Cultures were incubated at $37^{\circ} \mathrm{C}$ with $5 \%$ carbon dioxide for 48 hours. Supernatants were collected by centrifugation and measured by enzyme-linked immunosorbent assay (ELISA).

\section{Cytokine and Chemokine Measurement}

Murine IL-17A and interferon (IFN) $\gamma$ were measured in culture supernatants by ELISA using commercially available reagents and standards (Pharmingen, San Diego, CA; R\&D Systems, Minneapolis, MN; Peprotech Inc, Rocky Hill, $\mathrm{NJ}$ ). Sensitivities were between 15 and $50 \mathrm{pg} / \mathrm{ml}$. Murine CCL22 was measured in aqueous lung extracts by ELISA using commercial reagents (R\&D Systems). Aqueous extracts were prepared as previously described. ${ }^{16}$

\section{Immunohistochemical Staining}

Paraffin-embedded lung sections were deparaffinized in $100 \%$ xylene for 3 minutes and in a 1:1 solution of xylene and ethanol for 3 minutes. Sections were rehydrated in $100 \%, 95 \%, 75 \%$, and $50 \%$ ethanol solutions, 3 minutes each, and finally rinsed in PBS. Antigen retrieval used a 1:20 dilution of decloaker (Bullseye; Biocare Medical, Concord, CA) and incubation of sections at $125^{\circ} \mathrm{C}$ for 30 seconds, followed by a $90^{\circ} \mathrm{C}$ incubation for 10 seconds in a decloaking chamber (Biocare Medical, Concord, CA). Slides were rinsed in cold tap water after antigen retrieval and placed in PBS wash for 3 minutes. An avidin and biotin blocking kit (Biogenex, San Ramon, CA) and goat serum block (Biogenex) were used according to the manufacturer's instructions. Rabbit anti-mouse CCL22 antibody (Abcam, Cambridge, MA), diluted 1:50 in PBS, was incubated on sections for 1 hour 15 minutes at room temperature. Nonimmune rabbit IgG served as a parallel control. Secondary goat anti-rabbit alkaline phosphatase-conjugated antibody was diluted to 1:1000 in PBS and incubated for 20 minutes. Fast red substrate kit (Biogenex) was prepared and incubated at 20 minutes. Hematoxylin was used as the counterstain.

\section{Flow Cytometry and Intracellular Cytokine Staining}

Single-cell suspensions were prepared from lungs as previously described. ${ }^{17}$ Briefly, after perfusion with cold RPMI 1640 medium, lungs were excised, placed in cold RPMI 1640 medium, and then homogenized for 15 seconds in a blender (Waring). Homogenates were incubated with digestion medium containing RPMl 1640 medium, 10\% fetal bovine serum (Atlanta Biologicals, Norcross, GA), and 250-
$\mathrm{U} / \mathrm{ml}$ type IV collagenase (Sigma Aldrich) for 10 minutes at $37^{\circ} \mathrm{C}$. The digest was sieved through a $40-\mu \mathrm{m}$ cell strainer (BD Biosciences, San Jose, CA) and washed twice by centrifugation in RPMI 1640 medium. Single-cell suspensions were also prepared from freshly harvested spleens and lymph nodes by mechanical dissociation, as previously described. ${ }^{18}$ Total cell yields were determined by standard hemocytometric counting.

Monoclonal antibodies used included the following: fluorescein isothiocyanate-, phosphatidylethanolamine-, phosphatidylethanolamine-Cy5-, Pacific blue-, and antigen-presenting cell (APC)-conjugated anti-CD4 (GK1.5), anti-CD8a (53-6.7), anti-TCR $\alpha / \beta$ (H57-597), anti-TCR $\gamma / \delta$ (UC7-13D5), anti-NK1.1 (PK136), anti-IFN $\gamma$ (R46A2 and XMG1.2), anti-IL-4 (11B11 and BVD6-24G2), anti-IL-17 (TC11-18H10), anti-Foxp3 (FJK-16s), anti-CD62L (MEL14), anti-CD44 (IM7), anti-CD90.1 (HIS51), and antiCD90.2 (53-2.1) (BD Biosciences; or eBioscience, San Diego). All isotype controls and anti-CD16/CD32 (2.4G2) were from BD Biosciences. After blocking with anti-CD16/ CD32 for 5 minutes, cells were stained with fluorescentlabeled antibodies or isotype control antibodies in $2 \%$ fetal bovine serum-PBS staining buffer for 25 minutes at $4^{\circ} \mathrm{C}$. A multicolor flow cytometer (FACScan LSRII; BD Biosciences) with software (FlowJo; Tree Star, Ashland, OR) was used for data acquisition and analysis. Invariant NK T cells were identified using either fluorescein isothiocyanate-labeled (NIH Tetramer Core Facility, Atlanta GA) or phosphatidylethanolamine-fluorescent-labeled (Prolmmune, Bradenton, FL) CD1d tetramer (loaded and unloaded). Briefly, $100 \mu \mathrm{L}$ of staining buffer and $0.5 \mu \mathrm{L}$ of either loaded or unloaded (control) tetramer was added to each anti-CD16/CD32 blocked sample and then incubated for 30 minutes at $4^{\circ} \mathrm{C}$. After washing, a second staining for additional surface markers was performed. The NKT cells were defined as CD1tetramer $+\mathrm{TCR} \alpha / \beta+\mathrm{CD}^{-}$cells.

Intracellular flow cytometric analysis of lung and mediastinal lymph nodes cells was performed as previously described. ${ }^{19}$ Briefly, single-cell suspensions were incubated for 3 hours in complete medium in the presence of brefeldin A, $1 \mu \mathrm{g} / \mathrm{ml}$ (BD Biosciences). In some cases, cells were stimulated in culture before adding brefeldin A. Cells were harvested and stained for surface antigen expression before staining for intracellular cytokines. Intracellular cytokine staining was performed using a kit (Cytofix/Cytoperm Kit; $\mathrm{BD}$ Biosciences) according to the manufacturer's directions.

In vivo antigen presentation was detected using adoptive transfer of carboxyfluorescein succinimidyl ester-labeled CD4 ${ }^{+}$T cells (Invitrogen, Carlsbad, CA) from transgenic mice with OVA peptide-specific TCR (OT-II), as previously described. ${ }^{20}$ The number of analyzed events ranged from 500,000 to 1 million cells for all flow studies.

\section{RNA Purification and Real-Time RT-PCR Analysis}

RNA was isolated, reverse transcribed, and used for realtime PCR analyses, as previously described ${ }^{21}$ Analysis of the transcripts was performed by real-time PCR using a 
system (ABI PRISM 7000 Sequence Detection System; Applied Biosystems, Foster City, CA), as previously described..$^{16}$ The comparative threshold cycle method recommended by the manufacturer was adopted. Glyceraldehyde-3-phosphate dehydrogenase was used as the endogenous reference. All primer-probe sets were purchased commercially (Applied Biosystems). The thermal cycling condition was programmed according to the manufacturer's instructions. Transcript levels were expressed as arbitrary units and were calculated as previously described. ${ }^{22}$

\section{Statistical Analysis}

The Student's t-test was used for direct comparisons with a parallel control group and one-way analysis of variance for multigroup analyses. $P<0.05$ was considered significant.

\section{Results}

\section{CCR4 Agonists Are Expressed in Lungs during M. bovis BCG Infection}

In contrast to virulent Mycobacterium tuberculosis, which is uniformly fatal in most mouse strains, $M$. bovis BCG is an attenuated live vaccine strain and well tolerated, even by highly immunocompromised mice. Therefore, BCG provides a means to examine both inductive and elicitation stages of antimycobacterial immune responses in mice but is not useful for survival studies. In addition to multiple innate immune mechanisms activated in the early stages of $M$. bovis BCG pulmonary infection, BCG is known to elicit a highly polarized IFN $\gamma$ dominant adaptive response involving both $\mathrm{CD} 4^{+}$and $\mathrm{CD} 8^{+} \mathrm{T}$ cells. To determine the potential involvement of CCR4 in lungs after BCG exposure, we first assessed the temporal transcript expression of the two known agonists for this chemokine receptor, CCL17 (formerly thymus activated-regulated chemokine) and CCL22 (formerly macrophage-derived chemokine). As shown in Figure $1 \mathrm{~A}$, transcripts for both CCR4 agonists showed constitutive levels in preexposure lungs, with an increase after infection. There was significant CCL22 transcript induction at 1 week after infection, with levels increasing by nearly threefold and then declining thereafter with a trend to increased levels at 6 weeks; however, this was not statistically different from constitutive levels. CCL17 showed lower constitutive transcript expression than CCL22, but it also increased by nearly threefold by 1 week after infection and declined thereafter. The increase of CCR4 agonists at 1 week was associated with increasing levels of CCR4 transcript expression (Figure $1 \mathrm{~B})$, which peaked at 2 weeks and then declined thereafter. Thus, CCR4 agonists appear to be constitutively expressed chemokines, with BCG infection enhancing expression early after infection. The CCR4 agonist induction was similar in CCR4 knockout mice. Specifically, protein levels for CCL22 were measured in aqueous lung extracts by ELISA and revealed constitutive levels in naive lungs (ie, $394 \pm 40 \mathrm{pg} / \mathrm{ml}$ ); at 1 week of infection, this increased to $748 \pm 273$ and $766 \pm 264 \mathrm{pg} / \mathrm{ml}$ for WT and
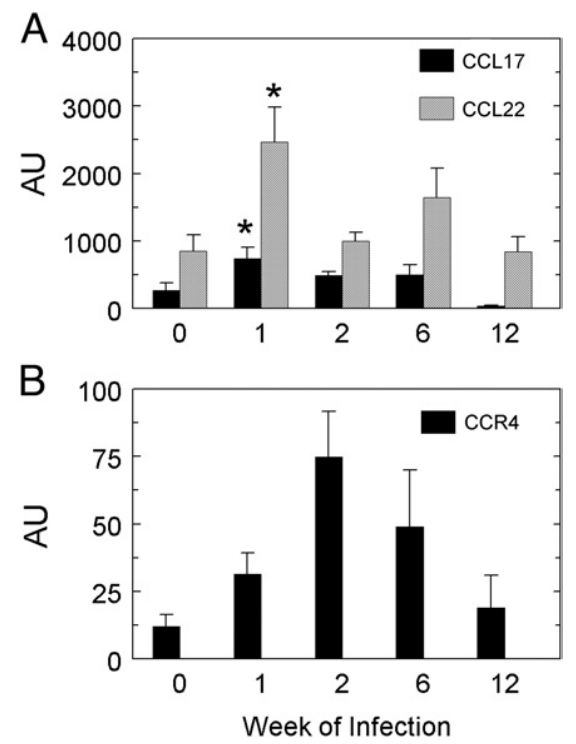

Figure 1. Time course of CCR 4 agonist and CCR 4 transcript expression in lungs of $M$. bovis BCG-infected mice. C57BL/ 6 mice were infected i.t. with $M$. bovis BCG, and groups of mice were harvested for analysis of CCL17, CCL22, and CCR4 transcripts in whole perfused lungs by RT-PCR. A, CCR4 agonist transcript levels; B, CCR 4 receptor transcript levels. Bars are mean $\pm \mathrm{SE}$ arbitrary units ( $n=5-6$ mice). ${ }^{*} P<0.05$ versus uninfected control (time 0 ).

CCR4 knockout mice, means and standard deviations, respectively.

Immunohistochemical detection of agonist expression was also performed. Antibodies suitable for immunohistochemical detection are available only for CCL22 (formerly macrophage-derived chemokine). By using this preparation, we examined expression in the lungs of naïve and BCG-infected mice. As shown in Figure 2A, CCL22 was constitutively expressed in the lungs of uninfected mice among scattered alveolar septal mononuclear cells. One week after infection with BCG, CCL22 was detected in mononuclear cells associated with inflammatory nodules, alveolar macrophages, and interstitial mononuclear cells (Figure 2, C, E, and G). Sections stained with control antibody are shown in Figures 2B, 2D, 2F and 2H. CCL22 was not observed in epithelial cells, smooth muscle, or endothelium at this time.

\section{CCR4 Knockout Mice Display Impaired Early Clearance of M. bovis BCG and Reduced Late Stage Inflammation}

Because CCR4 agonist expression was induced in lungs during BCG infection, we next examined the effect of CCR4 gene knockout on infection kinetics. Knockout $\left(\mathrm{CCR} 4^{-{ }^{-}}\right)$and control WT $\left(\mathrm{CCR} 4^{+/+}\right)$mice were exposed to organisms i.t. and then lungs were harvested for quantification of CFUs. As shown in Figure 3A, both $\mathrm{CCR} 4^{-1-}$ and $\mathrm{CCR} 4^{+/+}$mice were able to largely eliminate organisms by 12 weeks of infection; however, knockout mice showed a statistically significant (nearly $1 \mathrm{log}$ ) early impairment of clearance at 2 weeks. Because the adaptive response to mycobacteria does not manifest in lungs until after 2 weeks, ${ }^{23}$ this finding suggested that early innate resistance might be impaired in CCR $4^{-1-}$ mice. 


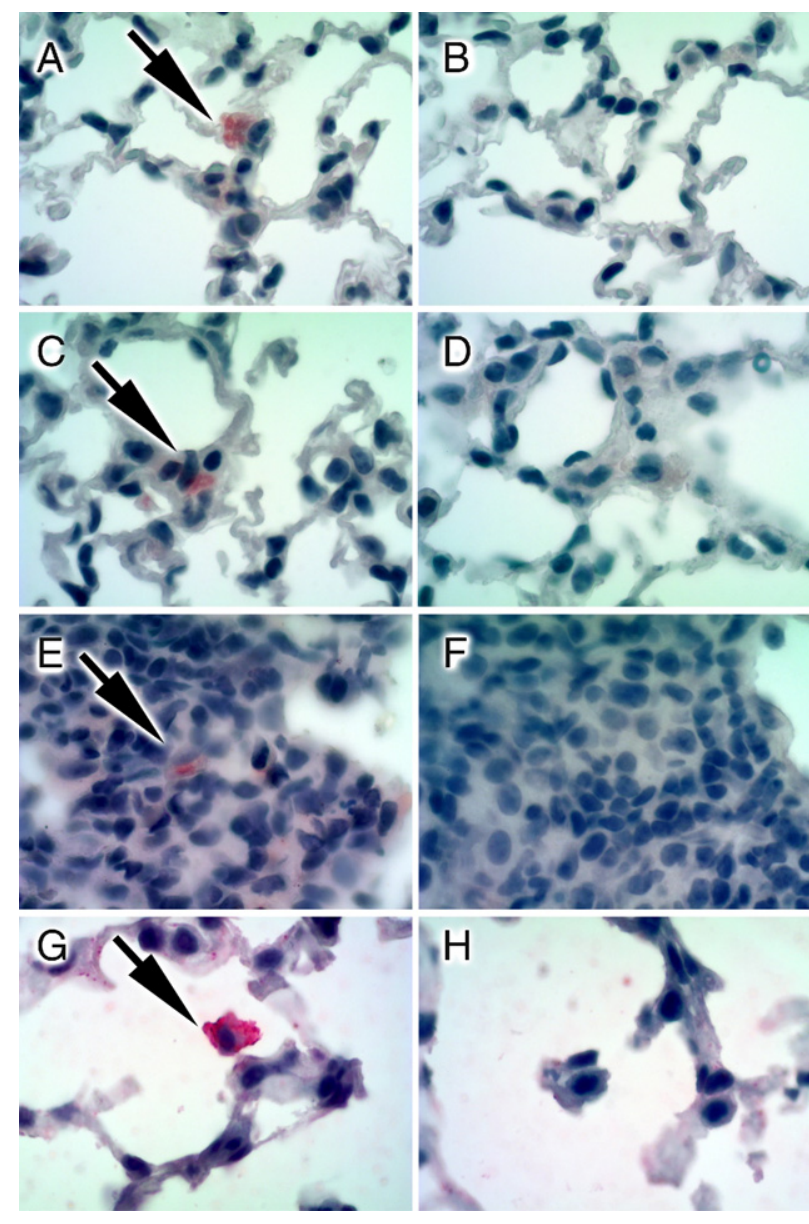

Figure 2. Immunohistochemical detection of CCL22 in naïve and $M$. bovis BCG-infected lungs. A: Uninfected mouse lung demonstrating constitutive CCL22 expression (arrow) among scattered septal interstitial mononuclear cells. B: Serial section stained with control rabbit IgG. C: At 1 week, BCGinfected lung showing positive interstitial cell (arrow) near a venule. D: Serial section stained with control rabbit IgG. E: At 1 week, BCG-infected lung showing positive mononuclear cell (arrow) in an inflammatory nodule. F: Serial section stained with control rabbit IgG. G: At 1 week, BCG-infected lung showing positive alveolar macrophage (arrow). H: Serial section stained with control rabbit IgG. Original magnification, $\times 600$. Arrows point to positively staining mononuclear cells.

When lungs were examined histologically, inflammation was comparable in both strains during the early elimination stage (2-4 weeks); thereafter, $\mathrm{CCR} 4^{-1-}$ mice showed less persisting inflammation in the late stage when residual lymphoid-rich inflammation predominated in control BCG-challenged lungs (Figure 3C). The histological impression was supported by quantification of cellularity of lung digests (Figure 3B). Therefore, CCR4 appeared to participate in the late ( $>4$ weeks) and innate $(<2$ weeks) stages, but no clear effects were apparent during the rapid clearance stage (2-4 weeks).

\section{CCR4 Knockout Impairs Innate Stage NK 1.1+ Effector Cell Activation}

In view of the impairment of early bacterial resistance, we surmised that CCR4 might contribute to the innate stage antimycobacterial response. Although an adaptive CD4 ${ }^{+}$ Th1 response is required for elimination of mycobacteria, it is well established that innate immune mechanisms participate in the early-stage antimycobacterial response. ${ }^{24}$ Natural killer CD1d-restricted NK T (invariant NK T) and $\gamma / \delta$ T cells are thought to retard early mycobacterial expansion. ${ }^{25-28}$ However, although these populations can slow bacterial growth, they are insufficient for complete resistance to infection-level inoculums. Phenotypic CCR4 expression has been described among all of these innate-stage populations. ${ }^{29-31}$ Based on these reports, we hypothesized that compromise of an innate component might be responsible for the transient impairment of mycobacterial clearance observed in $\mathrm{CCR} 4^{-1-}$ mice.

Initial flow cytometric analyses revealed no quantitative defect in recruitment of $\alpha / \beta \mathrm{T}, \gamma / \delta \mathrm{T}$, invariant NK T, or $\mathrm{NK} 1+$ cells to the lungs of knockout mice (Table). Of these populations, NK cells dominated numerically and reached a maximum at 1 week after infection (Figure 4A). Because NK functional activity requires induction of cytokine-producing capacity after interacting with APCs, ${ }^{32}$ we assessed NK1.1 + cells for expression of intracellular IFN $\gamma$ and IL-17. As shown in Figure 4, B and C, IFN $\gamma$ was the dominant cytokine expressed by CD4 ${ }^{-} \mathrm{NK}$ cells. The $\mathrm{IL}-17+\mathrm{NK}$ cells represented a minor population, with no differences detected between control and knockout mice. In contrast, $\mathrm{CCR} 4^{-1-}$ mice displayed a significant reduction in the activated IFN $\gamma+$ population, which persisted during the study period. This effect extended to both CD8+ and CD8 ${ }^{-}$NK cells (data not shown). This finding indicated that CCR4 was required for maximal NK activation but not recruitment during the innate-stage response to $M$. bovis BCG infection and provided a potential explanation for impaired clearance.

\section{CCR4 Knockout Impairs Late Stage CD4 ${ }^{+}$ Effector T Cell But Not $\gamma / \delta$ T-Cell Mobilization to Lungs}

Because $\mathrm{CCR}^{-1-}$ mice also displayed reduced late stage lung inflammation, we explored the contribution of CCR4 to later-stage cell-mediated antimycobacterial effector responses. To this end, $\mathrm{CCR} 4^{+/+}$and $\mathrm{CCR} 4^{-/-}$ mice were infected with $M$. bovis BCG and lungs were dispersed enzymatically, cultured with $M$. bovis PPD, and then analyzed by flow cytometry. Subpopulations of $T$ cells and intracellular expression of IFN $\gamma$ and IL-17 among those populations were measured during a 12week study period. As shown in Figure 5, the proportion of CD8 + and $\gamma / \delta+T$ cells reached a maximum at 2 weeks of infection and thereafter declined, with no differences observed between $\mathrm{CCR} 4^{+/+}$and $\mathrm{CCR} 4^{-/-}$mice (Figure 5, left column). In contrast, CD4 ${ }^{+}$T cells reached a maximum at 6 weeks, with reductions observed in $\mathrm{CCR}^{-1-}$ mice at this time. Both $\mathrm{IFN} \gamma+$ and $\mathrm{IL}-17+$ effector T cells were identified in lungs at 2 and 6 weeks of infection, representing early and late bacterial elimination stages (Figure 5, right column). In control and knockout mice, cytokine-positive cells were most frequent among $\mathrm{CD}^{+}{ }^{+}$and $\gamma / \delta+\mathrm{T}$ cells. The IFN $\gamma+$ cells were more dominant among $\mathrm{CD}^{+}{ }^{+} \mathrm{T}$ (Th1), whereas $\mathrm{IL}-17+$ cells were predominantly $\gamma / \delta$ T cells; however, CD4 ${ }^{+}$Th17 and IFN $\gamma+$ 


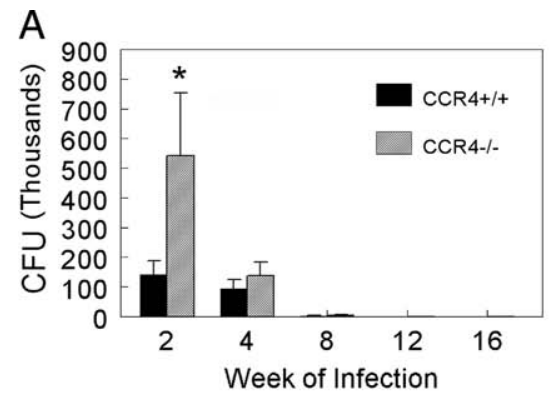

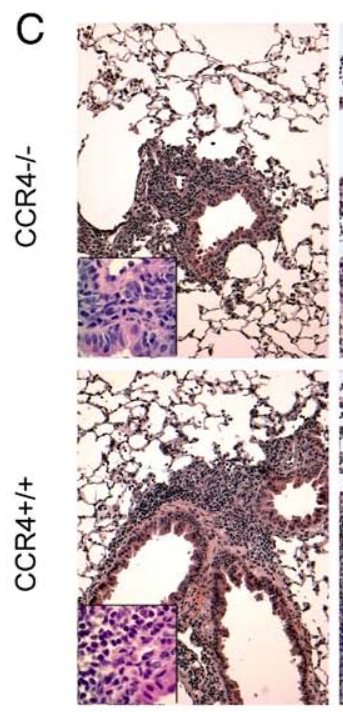

2

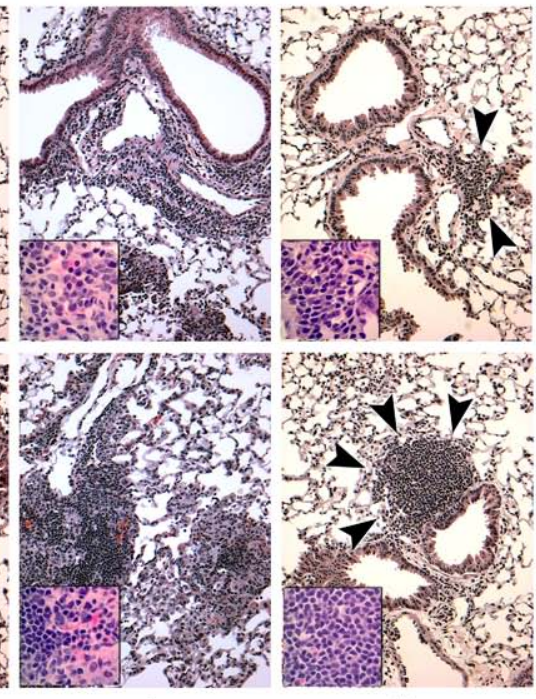

4
12

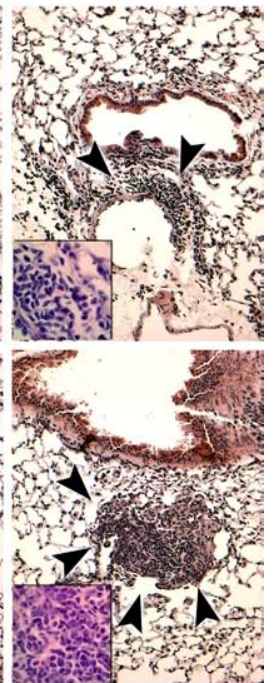

16

Week of Infection

Figure 3. Effect of CCR4 knockout on bacterial clearance and lung inflammation after $M$. bovis BCG infection. A: Postinfection bacterial clearance kinetics * $P<$ 0.0005 . B: Postinfection lung cells yields. Bars are mean \pm SD $(n=5-6$ mice per group). C: Histological appearance of lungs during early ( $2-4$ weeks) and late ( $>4$ weeks) clearance periods (hematoxylin-eosin stain, $\times 100$ magnification; insets, $\times 600$ magnification). Histologically, the response is predominantly mononuclear and shifts to a lymphoid-dominant inflammation after 4 to 6 weeks. Arrows point to lymphoid-rich nodules that were smaller in knockout mice. ${ }^{*} P<0.05$ versus the parallel control $\left(\mathrm{CCR} 4^{+/+}\right)$group.

$\gamma / \delta$ T cells were also present, but as lesser components. Comparing left with right columns (Figure 5), although $\gamma / \delta \mathrm{T}$ cells represented only $1 \%$ to $2 \%$ of lung cells, many $(>90 \%)$ of $\gamma / \delta$ T cells were $\mathrm{IL}-17+$. In the early stage (2 weeks), cytokine-positive cell populations were comparable among control and knockout mice. In contrast, by 6 weeks, $\mathrm{CCR}^{-1-}$ mice displayed $70 \%$ reductions of IFN $\gamma+\mathrm{CD}^{+} \mathrm{T}$ cells $\left(1.1 \% \pm 0.3 \%\right.$ versus $0.3 \% \pm 0.1 \%$ for $\mathrm{CCR}^{+/+}$and $\mathrm{CCR}^{-1-}$ mice, respectively), although IL $17+\gamma / \delta \mathrm{T}$ cells were unaffected. Interestingly, at 6 weeks, a significant reduction was also detected in the minor $1 \mathrm{~L}-17+\mathrm{CD} 4^{+}$ population $(0.14 \% \pm 0.03 \%$ and $0.06 \% \pm 0.02 \%$ for $\mathrm{CCR}^{+/+}$and $\mathrm{CCR} 4^{-/-}$mice, respectively). The effector cell response to BCG was highly polarized toward IFN $\gamma$ and IL-17-producing cells, with no IL-4+ cells detected (data not shown). These data suggested that CCR4 supported late stage $\mathrm{CD}^{+}{ }^{+}$Th1 and Th17, but not $\gamma / \delta$ Teffector cells, in challenged lungs.

\section{CCR4 Mice Display Normal CD4+ $T$-Cell Proliferative Responses to Recombinant BCG-OVA and Effector/Memory Cell Generation}

The reduction in late stage Th effectors was potentially due to an impaired capacity to produce them. To test the induction of the adaptive response of $\mathrm{CCR} 4^{-1-}$ mice, we initially assessed Ag-presenting capacity using transgenic T-cell transfer and infection with recombinant mycobacteria. Control and knockout mice were infected with recombinant BCG-expressing OVA peptides. To identify the optimal period of T-cell proliferation in draining lymph nodes, groups of mice were infected with 1 million CFUs of recombinant BCG-OVA and administered OT-II cells on days 0,7 , and 13; then, lymph nodes were analyzed on days 6,14 , and 21 , respectively. As reported for $M$ tuberculosis infection of mice, ${ }^{23}$ our studies showed that optimal Ag presentation is delayed in draining lymph nodes until beyond days 7 to 10 of infection (Supplemental Figure S1 at, see http://ajp.amjpathol.org). Thus, WT and knockout mice were administered carboxyfluorescein succinimidyl ester-labeled CD90 congenic D10.11 OVA-specific transgenic CD4 ${ }^{+} \mathrm{T}$ cells on day 13 after challenge with recombinant BCG-OVA. Then, on day 21 , mice were sacrificed and draining lymph nodes and spleens were subjected to flow cytometric analysis. Figure $6 \mathrm{~A}$ shows that $\mathrm{CCR} 4^{+/+}$and $\mathrm{CCR} 4^{-1-}$ mice displayed similar degrees of proliferation, with at least four generations detected. Moreover, proliferation was most apparent in draining lymph nodes than spleens, consistent with the lung being the primary site of $\mathrm{Ag}$ insult. No proliferation was

Table 1. Lung T- and NK Cell Populations on Day 8 of Mycobacterium bovis BCG Challenge*

\begin{tabular}{lcccc}
\hline Genotype & TCR $\alpha / \beta$ T cells & TCR $\gamma / \delta$ T cells & iNK T cells & NK1+ cells \\
\hline CCR4 $^{+/+}$ & $443 \pm 116$ & $17.4 \pm 5.3$ & $9.1 \pm 2.4$ & $775 \pm 337$ \\
CCR4 $^{-1-}$ & $496 \pm 89$ & $20.7 \pm 3.3$ & $9.6 \pm 2.4$ & $834 \pm 196$ \\
\hline
\end{tabular}

NK, natural killer; BCG, Bacille-Calmette-Guerin; TCR, T cell receptor; iNK, invariant NK; CCR4, cysteine-cysteinyl chemokine receptor 4.

${ }^{*}$ Data are given as mean \pm SE cell number (given in thousands per lung), derived from five to six lungs. 
A

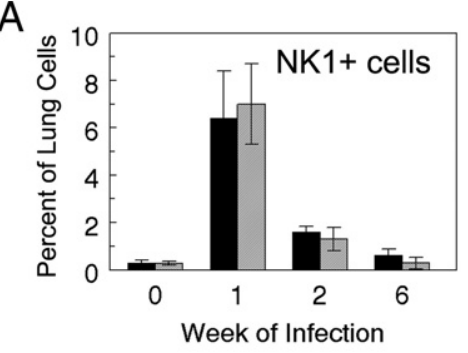

C

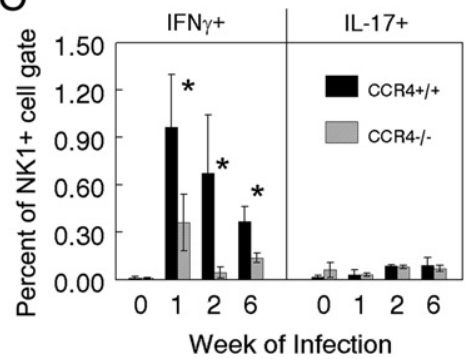

B

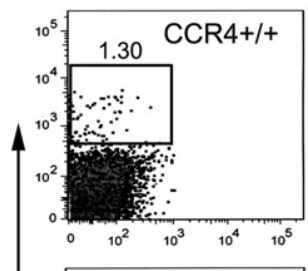

NK1+ gate

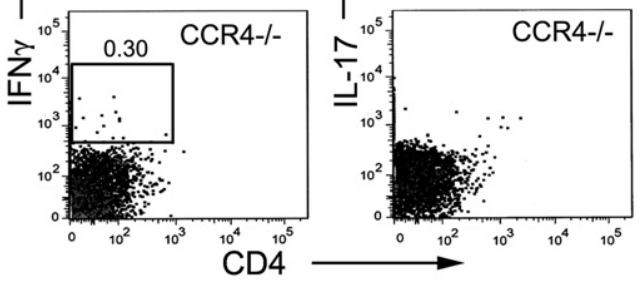

Figure 4. The CCR4 knockout impairs NK cell activation during the innate-stage response to $M$ bovis BCG infection. A: Time course of appearance of NK1.1+ cells in lungs of $M$. bovis BCG infected $\mathrm{CCR}^{+/+}$and CCR4 $4^{-/-}$mice. Perfused lungs were enzymatically dispersed and subjected to flow cytometric analysis. B: Representative scattergrams of IFN $\gamma$ - and IL-17-positive cells in the NK1.1+ gate at week 1 of infection; abscissa FL1, ordinate FL2. A total of 500,000 events were analyzed. C: The IFN $\gamma$ and IL-17 expression by NK cells in lungs of $M$. bovis BCGinfected $\mathrm{CCR} 4^{+/+}$and $\mathrm{CCR} 4^{-/-}$mice. Bars are mean $\pm \mathrm{SD}(n=4-6$ mice $) .{ }^{*} P<0.05$ versus the parallel control $\left(\mathrm{CCR}^{+/+}\right)$group. elicited with nonrecombinant BCG-WT organisms. Thus, the CCR4 knockout environment fully supported Ag presentation.

Despite normal Ag presentation, reduced numbers of $\mathrm{CD}^{+}{ }^{+}$effector cells in BCG-challenged lungs might be secondary to impaired differentiation of effectors in draining lymph nodes. To explore this, we examined the ca-
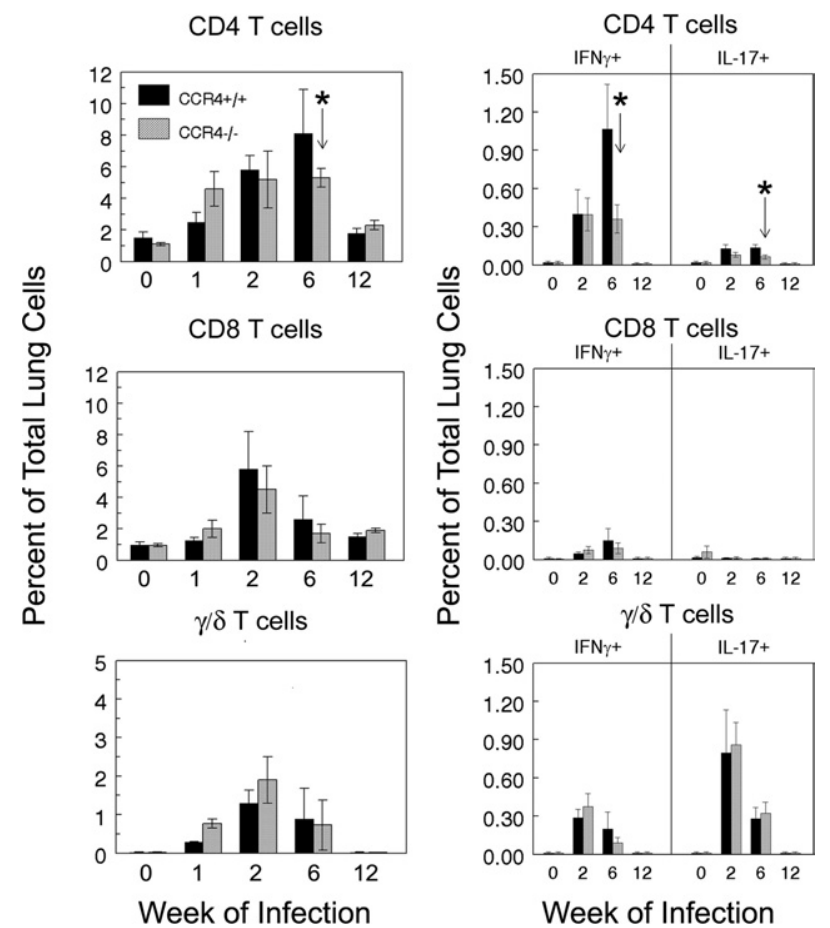

Figure 5. Effect of CCR 4 knockout on effector T-cell mobilization to lungs after $M$. bovis BCG infection. After i.t. infection, groups of mice were harvested at designated points for enzymatic dispersal of lungs, followed by flow cytometric characterization of major T-cell populations. Antigen-elicited IFN $\gamma$ - and IL-17-producing effector cells were identified by intracellular cytokine staining of PPD-stimulated cells. Bars are mean \pm SD $(n=5-6$ mice). ${ }^{*} P<0.05$ verses the parallel control $\left(\mathrm{CCR} 4^{+/+}\right)$group. A total of 500,000 events were analyzed. pacity of $\mathrm{CCR} 4^{-1-}$ mice to generate effector cells in draining mediastinal lymph nodes. Groups of $\mathrm{CCR} 4^{+/+}$ and $\mathrm{CCR} 4^{-1-}$ mice were infected, and their lymph nodes were subjected to intracellular cytokine staining to define the distribution of effector cell populations at 2 weeks. Figure 6B shows that both $\mathrm{CCR}^{+/+}$and $\mathrm{CCR}^{-1-}$ mice had similar numbers and types of effectors. The dominant IFN $\gamma+$ population was $\mathrm{CD}^{+}{ }^{+}$Th1 cells, with CD8+ and $\gamma / \delta$ T cells comprising the remaining IFN $\gamma$ producers. The IL-17 producers were largely absent from lymph nodes at this time. Levels of Foxp3+ CD4 ${ }^{+} \mathrm{T}$ cells were also similar in lymph nodes at 2 weeks $(2.9 \% \pm 0.3 \%$ and $3.2 \% \pm$ $0.2 \%$ for $\mathrm{CCR} 4^{+/+}$and CCR $4^{-1-}$ mice, respectively; $n=$ 4 per group). Thus, CCR4 knockout did not compromise the induction or spectrum effector cells generated in draining lymph nodes.

We also assessed the circulating Th memory cell compartment by comparing levels of CD $4+\mathrm{CD} 44^{\text {hi }} \mathrm{CD}^{2} 2 \mathrm{~L}^{\text {lo }}$ cell in spleens at 12 weeks after infection, when bacteria are largely eliminated. As shown in Figure $6 \mathrm{C}$, most $\mathrm{CD}^{+} \mathrm{T}$ cells in spleens were CD62 L ${ }^{\text {hi }}$, consistent with naïve T cells, but approximately $10 \%$ were CD4+CD62L lo, which were greater than $90 \%$ CD44+, consistent with Th memory cells. The CCR4 ${ }^{-1-}$ mice showed no gross changes in this compartment. Thus, the late stage defect in knockout mice was likely due to influences on local recruitment, activation, or survival.

\section{Mycobacterium bovis BCG-Infected CCR4 Knockout Mice Display Impaired Late Stage IL-17 Production in Lymph Node Cultures}

To assess late stage events in lymphoid tissue, we harvested draining mediastinal lymph nodes over 16 weeks of infection and cultured them with $M$. bovis PPD to elicit cytokines. At 48 hours, cell-free culture supernates were harvested and cytokine levels were measured by standard enzyme immunoassay as a gross measure of the 
A

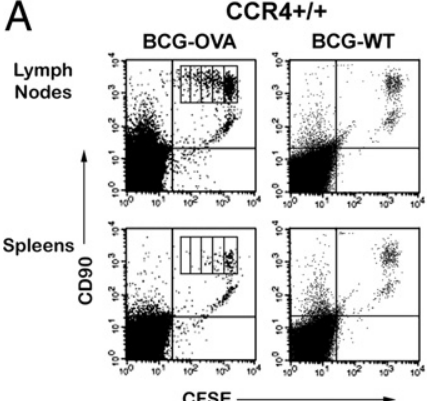

CFSE
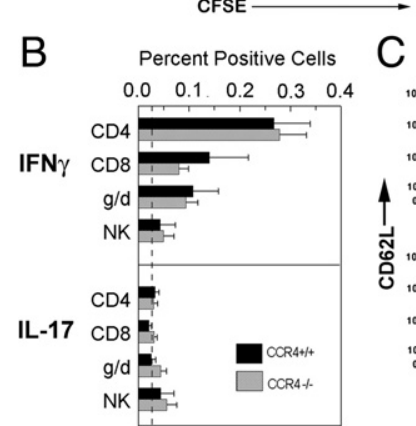

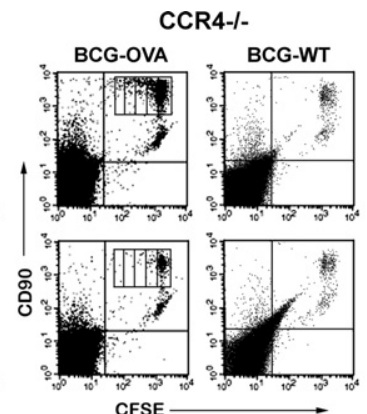

C $\operatorname{TCR} \alpha / \beta \mathrm{CD} 4+$ gate
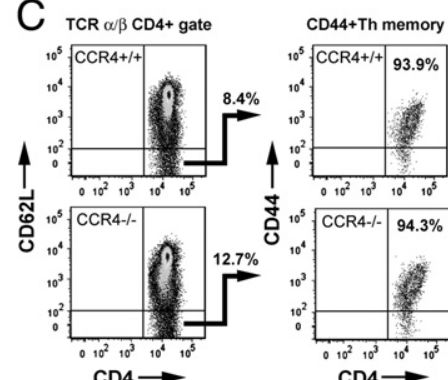

Figure 6. The CCR 4 knockout does not affect CD4+T-cell proliferation or effector/memory cell generation after $M$. bovis BCG infection. A: Transgenic T-cell proliferation. The CCR $4^{+/+}$and $\mathrm{CCR}^{-/-}$mice were exposed to 1 million recombinant $M$. bovis BCG-OVA or control BCG i.t.; on day 13, the mice received 5 million carboxyfluorescein succinimidyl ester-labeled CD $4^{+}$ CD90.1+ OT-II transgenic T cells. On day 21, draining lymph nodes and spleens were subjected to flow cytometric analysis. Representative scattergrams are shown. One million events were analyzed. B: The IFN $\gamma$ - or IL-17-producing effector populations in draining lymph nodes. The $\mathrm{CCR}^{+/+}$and $\mathrm{CCR}^{-/-}$mice were exposed to 1 million WT BCG; 2 weeks later, the draining lymph node was harvested, dispersed, and analyzed for PPD-elicited cytokine-producing cells using intracellular cytokine staining. Bars are mean $\pm \mathrm{SD}(n=5-6$ mice $)$. The dashed line indicates baseline staining with isotype control antibody. C: Flow cytometric assessment of $\mathrm{CD}^{+}{ }^{+}$splenic T cells with CD $62 \mathrm{~L}^{\mathrm{lo}} \mathrm{CD} 44+$ memory phenotype at 12 weeks of infection. Splenic cell yields were comparable among knockout and controls. Representative scattergrams are shown.

effector responses. Assays were performed for IL-2, IL-4, $\mathrm{IL}-17$, and IFN $\gamma$. Of the cytokines assayed, only IFN $\gamma$ and IL-17 were produced in substantial amounts. As shown in Figure $7 \mathrm{~A}, \mathrm{CCR}^{+/+}$and $\mathrm{CCR} 4^{-/-}$mice had similar lymph node cell yields during the study period. The pattern of nodal IFN $\gamma$ production was similar among the strains, characterized by the highest levels of IFN $\gamma$ at 2 weeks when adaptive effectors appear; subsequently, these disappeared from nodes at 4 to 8 weeks, with partial reappearance beyond 8 weeks in the resolution stage (Figure 7B). This pattern is consistent with the generation and emigration of IFN $\gamma+$ effectors, with later appearance of a circulating memory population. Interestingly, IL-17 became more prominent in lymph node cultures after 8 weeks, with $\mathrm{CCR} 4^{-1-}$ mice showing significantly reduced levels (Figure $7 \mathrm{C}$ ). The IFN $\gamma$ levels also trended lower during this time but did not reach statistical significance. Intracellular cytokine staining of lymph node populations indicated that IL-17 was primarily associated with $\mathrm{CD}^{+} \alpha / \beta$ T cells, consistent with Th17 cells (data not shown). These findings suggested that BCG leads to late stage induction of Th17 cells, whose expression was impaired in $\mathrm{CCR} 4^{-1-}$ mice.

\section{CCR4 Knockout Mice Display an Impaired Adaptive Granuloma Recall Response}

As a live vaccine, BCG should establish long-term adaptive T-effector memory cells with the capacity to elicit a recall granulomatous response. Regarding mycobacterial infection, a hypersensitivity-type granulomatous response in the lungs is generally thought to represent a protective response that contains and destroys organisms. To test the role of CCR4 in the local recall response, we used a well-characterized model in which granulomas are elicited with mycobacterial Ag-coated beads. ${ }^{15} \mathrm{Un}$ like rechallenge with bacilli, this approach provides a highly sensitive indicator of inflammation through synchronization and control of lesion numbers. Briefly, mice were exposed i.t. to BCG; then, in the postelimination phase (20 weeks), mice were challenged i.v. with 6000 $M$. bovis PPD-coated beads to elicit synchronized granulomas. We first determined the induction of CCR4 agonist transcripts in lungs of PPD bead-challenged mice. As shown in Figure 8A, during recall granuloma formation,
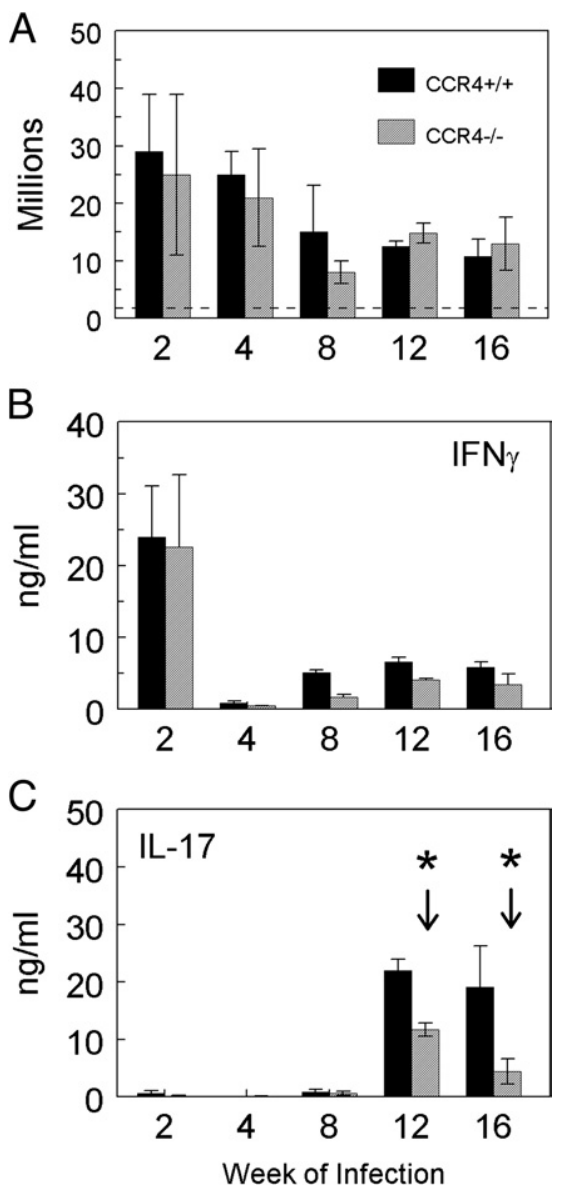

Figure 7. Effect of CCR4 knockout on draining lymph node cell yields and cytokine production after $M$. bovis BCG infection. After i.t. infection, groups of mice were harvested at designated points and mediastinal draining lymph nodes were collected, counted, and prepared for culture with PPD antigen. After 48 hours, culture supernates were collected by centrifugation and assayed for cytokines by enzyme immunoassay. A: Total lymph node cell yields. The dashed line indicates the average yield from naïve lymph nodes. B: The IFN $\gamma$ levels. C: The IL- 17 levels. Bars are mean \pm SD $(n=5-6$ mice). ${ }^{*} P<0.05$ versus the parallel control $\left(\mathrm{CCR} 4^{+/+}\right)$group. 
A

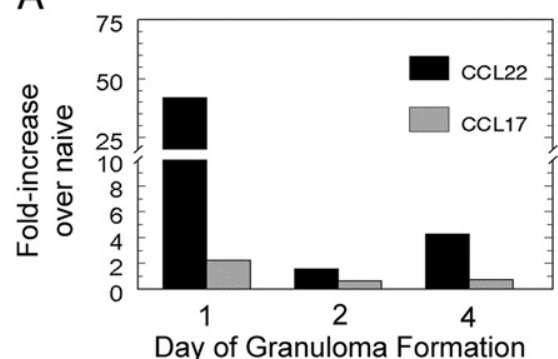

B

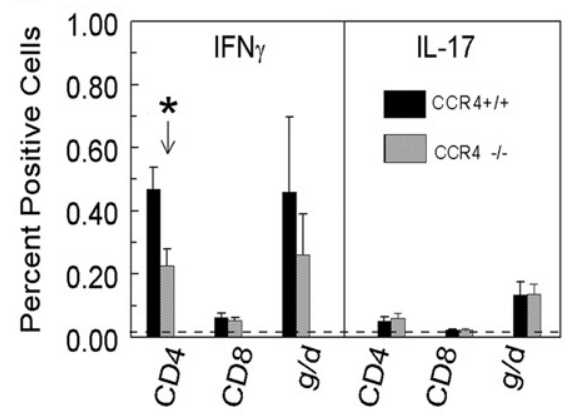

C

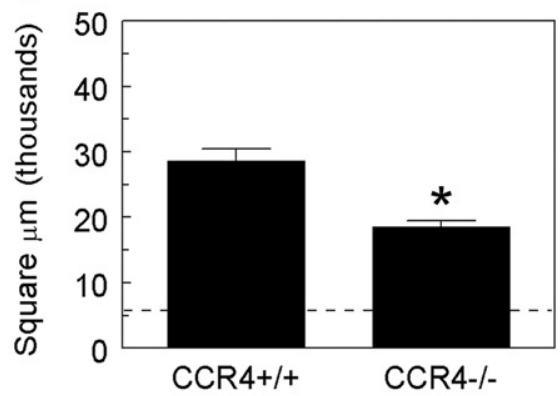

$\mathrm{D}$

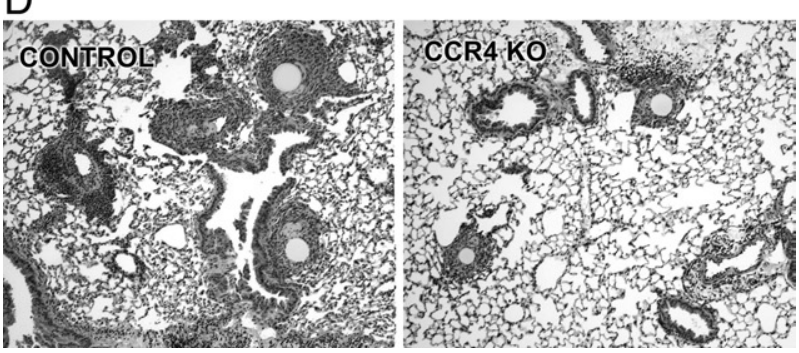

Figure 8. The CCR4 knockout impairs the antimycobacterial recall granuloma response. A: Time course of CCR4 agonist transcript induction after PPD-bead challenge of BCG-sensitized mice. Bars are fold increases over levels in naïve lungs. A representative study is shown. B: The IFN $\gamma$ - and IL-17-producing effector cells in lungs of day 2 PPD-bead-challenged BCGsensitized CCR $4^{+/+}$and CCR $4^{-/-}$mice. Bars are mean $\pm \mathrm{SD}(n=4$ mice per group). C: Cross-sectional area of day 4 PPD-bead recall granulomas in BCG-sensitized CCR $4^{+/+}$and CCR $4^{-/-}$mice. Bars are mean $\pm \mathrm{SD}(n=5$ mice per group). ${ }^{*} P<0.05$ versus the parallel control $\left(\mathrm{CCR} 4^{+/+}\right)$group. The dashed line indicates the average area occupied by the bead. D: Histological appearance of day 4 PPD-bead recall granulomas in BCG-sensitized CCR $^{+/+}$and CCR $4^{-/-}$mice (hematoxylin-eosin stain, $\times 100$ magnification).

CCL22 and CCL17 transcripts were induced in lungs by 1 day; thereafter, they declined.

In view of rapid agonist induction, BCG-sensitized $\mathrm{CCR}^{+/+}$and $\mathrm{CCR} 4^{-/-}$mice were bead challenged and lungs were analyzed for cytokine-producing cells on day 2. As shown in Figure 8B, reduced levels of IFN $\gamma+$ cells were observed in $\mathrm{CCR} 4^{-1-}$ mice. The IFN $\gamma+\gamma / \delta$ T cells were also detected in the PPD-bead-challenged lungs, but a statistically significant reduction of this population could not be established. When granulomas were measured morphometrically on day 4 , lesion size was significantly reduced in $\mathrm{CCR}^{-1-}$ mice (Figure 8, C and D). Because $\mathrm{CCR}^{-1-}$ mice could adequately generate effector/memory Th cells, the findings suggested that CCR4 was required for localization, activation, or survival of $\mathrm{CD}^{+}$effector memory $\mathrm{T}$ cells within the lung during the organ-based granuloma recall response.

\section{Discussion}

Initial optimism about identifying cellular subset-restricted chemokine receptors has been dampened as the complexity and pleomorphic nature of these receptors become more apparent. Yet, several chemokine receptors have clearly important physiological functions. Among these receptors, CCR4 was initially described as a Th2 cell restricted chemokine receptor. ${ }^{33,34}$ However, accumulating evidence indicates it has wider expression and function. In this vein, a functional role for CCR4 in a murine model of mycobacterial Ag-elicited granuloma formation was previously reported. ${ }^{3}$ In that study, it was demonstrated that CCR4 was expressed by mycobacterial Ag-elicited Th1 cells. Subsequently, Qiu et al ${ }^{35}$ demonstrated strong induction of CCR4 in lungs and draining lymph nodes of macaque monkeys infected with $M$. tuberculosis associated with IFN $\gamma$ and IL-17 expression but not IL-4 expression. In the present study, we wanted to determine more specifically the functional role of CCR4 in the response to a live $M$. bovis BCG infection. Our findings are novel and point to a physiological role for CCR4 in supporting organ-based effector cell responses in innate and late stages of the antimycobacterial response.

We first established constitutive and induced CCR4 agonist expression in lungs after $M$. bovis BCG infection. The source of CCL22 was determined to be mainly large mononuclear cells in interstitium and inflammatory foci, consistent with the description of this chemokine as derived from macrophages and myeloid DCs. ${ }^{36}$ We then extensively tested the effect of CCR4 gene knockout on various aspects of the host response. Knockout mice displayed transiently impaired innate stage bacterial control, but the early adaptive clearance stage was unaffected. Thereafter, in the late stage when most bacteria were eliminated, CCR4 ${ }^{-1-}$ mice displayed reduced smoldering inflammation. These observations were particularly important because they suggested that although CCR4 was not required for effector cell induction, it appeared to support long-term inflammatory and homeostatic effector cell functions in peripheral organs. The presence of both constitutive and induced expression of CCR4 agonists is consistent with such a role.

Our subsequent analyses appeared to support this hypothesis and can be interpreted in the context of an evolving T-cell response. Although many aspects of the 
induction of T-cell memory remain unclear, it is known that $M$. bovis BCG induces organ-based T effector/memory and long-lived lymphoid tissue homing central memory T cells. ${ }^{37}$ Our studies demonstrated the induction of effector T cells in draining lymph nodes by 2 weeks after BCG infection, followed by their disappearance. By using OVA-peptide-specific transgenic TCR CD4 ${ }^{+} \mathrm{T}$-cell transfer, we confirmed that the CCR4 knockout environment could support primary adaptive T-cell proliferation. In addition, intracellular cytokine staining demonstrated no defect in the frequency of key effector cell populations within those lymph nodes. During the early adaptive elimination stage (2-4 weeks), effector cells were equivalently delivered to the infected lungs of $\mathrm{CCR} 4^{+/+}$and $\mathrm{CCR} 4^{-1-}$ mice. The latter was associated with rapid bacterial elimination, which was CCR4 independent. It was only in the late stage ( $\geq 6$ weeks) that $\mathrm{CCR} 4^{-/-}$mice displayed abrogated inflammation associated with reduced IFN $\gamma$ - and IL-17-producing $\mathrm{CD} 4^{+} \mathrm{T}$ cells and an impaired recall granulomatous response in lungs.

Our observations may relate to $\mathrm{CD} 4^{+} \mathrm{T}$-effector/memory cell function at different stages of Ag burden. Specifically, in the early elimination stage, there are abundant $\mathrm{Ag}$ and costimulatory cytokines to activate effector cells. Although most effector cells are presumed to die in the target organ after activation, clearly a component persists beyond the early stage when bacteria were largely eliminated. This population was compromised in lungs of $\mathrm{CCR} 4^{-1-}$ mice. In the skin, CCR4 reportedly promotes development or maintenance of T-effector/memory cells. ${ }^{11} \mathrm{~A}$ similar situation may apply to the lung environment. Maintenance of T effector/memory in mycobacterial infection is purported to depend on low-level Ag persistence involving interactions with organ-based Agpresenting cells. ${ }^{38}$ Moreover, Katou et al ${ }^{39}$ reported that CCR4 was required for optimal clustering of DCs and T cells in inflamed skin and lymphoid tissues. These reports are consistent with a recent study ${ }^{3}$ indicating that CCR4 expression was required by both APC and CD4+T cells for optimal T-effector activation. It is reasonable to speculate that in the late elimination stage when Ag burden is low, T-effector/memory function becomes more dependent on constitutive CCR4-mediated interactions with DCs, which are rich sources of CCR4 agonists. ${ }^{36}$ Furthermore, the constitutive expression of CCR4 agonists in the lung may promote long-term steady-state T-cell-DC interactions, allowing local activation of tissue homing adaptive or innate effector cells when antigen is present.

In addition to conventional TCR $\alpha / \beta+\mathrm{T}$ cells, $M$. bovis BCG is known to elicit a potent TCR $\gamma / \delta+$ T-cell response in mice. ${ }^{28}$ Our finding that TCR $\gamma / \delta+$ cytokine-producing $\mathrm{T}$ cells were unaffected in CCR4 ${ }^{-1-}$ mice is consistent with this population having different migratory and activation requirements than conventional $\mathrm{CD} 4^{+} \mathrm{T}$-effector cells. Indeed, TCR $\gamma / \delta+\mathrm{T}$ cells express predominantly CCR5 and CCR9, respond directly to microbial products, and promote maturation of immature DCs. ${ }^{40,41}$ The $\mathrm{TCR} \gamma / \delta+\mathrm{T}$ cells reached a maximum frequency in lungs at 2 weeks, were broadly activated, and were subsequently supplanted by conventional T cells, consistent with a role in a transition stage between innate and adaptive immunity.

Our finding of late stage appearance of PPD-responsive IL-17-producing cells in lymph nodes of $M$. bovisinfected mice was novel, and the abrogation of this population in $\mathrm{CCR} 4^{-1-}$ mice was unexpected. This finding suggests that CCR4 supports sustenance or activation of a lymph node homing memory population. Although preliminary studies indicate that this is a Th17 population, precise characterization regarding central versus effector memory phenotype has yet to be performed. Although we detected few IL-17+ effectors on day 2 of PPD-bead recall granuloma formation, compromise of a Th17 memory response might have relevance to the recall response. The Th17 cells are insufficient for mycobacterial resistance but have been reported to augment the Th1 antimycobacterial recall response. ${ }^{42}$ Detailed kinetic studies will be needed to determine whether compromise of Th17 memory cells in CCR4 ${ }^{-1-}$ mice contributed to the impaired Th1 mobilization in the late-stage PPD-bead granuloma recall response.

Finally, CCR4 ${ }^{-1-}$ mice displayed impaired mycobacterial control in the preadaptive stage of the response ( $0-2$ weeks), which we hypothesized was related to $a b-$ rogation of innate resistance. It is well established that several innate response mechanisms can control the early expansion of mycobacteria; among these mechanisms, NK cells are thought to be most influential. ${ }^{24}$ Indeed, we observed an early mobilization of NK cells to BCG-challenged lungs, reaching a maximum at 1 week and preceding the maximum appearance of $\mathrm{TCR} \gamma / \delta+$, $\mathrm{CD} 8+$, and $\mathrm{CD}_{4}^{+} \mathrm{T}$ cells. Although $\mathrm{CCR} 4^{-1-}$ mice showed no defect in absolute numbers of NK cells, they did display impaired NK activation, manifested by reduced IFN $\gamma$ expression, providing an explanation for the observed defective innate resistance. Because CCR4 is expressed by NK cells ${ }^{29,43}$ and NK activation, like T-cell effector activation, is thought to involve local interactions with APCs, ${ }^{32}$ compromised NK function might be related to impaired interactions with organ-based DCs. Infection of mice with virulent $M$ tuberculosis overwhelms NK celland adaptive T-cell-mediated resistance. ${ }^{25}$ However, in humans, innate and adaptive resistance is more effective because only $20 \%$ of exposed individuals develop disease. ${ }^{44}$ It is conceivable that activated NK cells serve as an early source of IFN $\gamma$ to promote bacterial killing within infected phagocytes.

Based on our findings and published reports, we propose a unified hypothetical model in which CCR4 is not required for organ homing but rather mediates contacts of innate and memory effector cells with DCs in the lung interstitium. Such a scenario would provide a steady-state organ-based sentinel function in which innate-stage NK and late stage $\mathrm{CD}^{+}{ }^{+} \mathrm{T}$-memory/effector cells interact with DCs. The activation of available effectors would occur when DCs are triggered by pathogen-associated stimuli. In the setting of low levels of persisting Ag, such a model could provide a means to sustain chronic inflammation and support organbased memory populations, also known as "effector lymphoid tissue." If this model is substantiated, CCR4 would be a potential target for the treatment of chronic smoldering 
inflammatory conditions and manipulation of antipathogen effector populations.

\section{Acknowledgments}

We thank Erin Wonderly, B.A., Cynthia Baker-Brown, A.O.S., and Sarah Mahoney, B.S., for their expert histological support.

\section{References}

1. Purandare AV, Somerville JE: Antagonists of CCR4 as immunomodulatory agents. Curr Top Med Chem 2006, 6:1335-1344

2. Chvatchko Y, Hoogewerf AJ, Meyer A, Alouani S, Juillard P, Buser R Conquet $F$, Proudfoot AE, Wells TN, Power CA: A key role for CC chemokine receptor 4 in lipopolysaccharide-induced endotoxic shock. J Exp Med 2000, 191:1755-1764

3. Freeman CM, Stolberg VR, Chiu BC, Lukacs NW, Kunkel SL, Chensue SW: CCR4 participation in Th type 1 (mycobacterial) and Th type 2 (schistosomal) anamnestic pulmonary granulomatous responses. J Immunol 2006, 177:4149-4158

4. Andrew DP, Ruffing N, Kim CH, Miao W, Heath H, Li Y, Murphy K, Campbell JJ, Butcher EC, Wu L: C-C chemokine receptor 4 expression defines a major subset of circulating nonintestinal memory $T$ cells of both Th1 and Th2 potential. J Immunol 2001, 166:103-111

5. Schaniel C, Sallusto F, Ruedl C, Sideras P, Melchers F, Rolink AG: Three chemokines with potential functions in $T$ lymphocyte-independent and -dependent B Iymphocyte stimulation. Eur J Immunol 1999, 29:2934-2947

6. Lieberam I, Forster I: The murine beta-chemokine TARC is expressed by subsets of dendritic cells and attracts primed CD4+ T cells. Eur J Immunol 1999, 29:2684-2694

7. Iellem A, Colantonio L, D'Ambrosio D: Skin-versus gut-skewed homing receptor expression and intrinsic CCR4 expression on human peripheral blood CD4+CD25+ suppressor T cells. Eur J Immunol 2003, 33:1488-1496

8. Acosta-Rodriguez EV, Rivino L, Geginat J, Jarrossay D, Gattorno M Lanzavecchia A, Sallusto F, Napolitani G: Surface phenotype and antigenic specificity of human interleukin 17-producing $\mathrm{T}$ helper memory cells. Nat Immunol 2007, 8:639-646

9. Campbell JJ, Haraldsen G, Pan J, Rottman J, Qin S, Ponath P, Andrew DP, Warnke R, Ruffing N, Kassam N, Wu L, Butcher EC: The chemokine receptor CCR4 in vascular recognition by cutaneous but not intestinal memory T cells. Nature 1999, 400:776-780

10. Vestergaard C, Bang K, Gesser B, Yoneyama H, Matsushima K, Larsen CG: A Th2 chemokine: TARC, produced by keratinocytes may recruit CLA+CCR4+ lymphocytes into lesional atopic dermatitis skin. J Invest Dermatol 2000, 115:640-646

11. Baekkevold ES, Wurbel MA, Kivisakk P, Wain CM, Power CA, Haraldsen $\mathrm{G}$, Campbell JJ: A role for CCR4 in development of mature circulating cutaneous $T$ helper memory cell populations. J Exp Med 2005, 201:1045-1051

12. Jakubzick C, Wen H, Matsukawa A, Keller M, Kunkel SL, Hogaboam CM: Role of CCR4 ligands: CCL17 and CCL22, during Schistosoma mansoni egg-induced pulmonary granuloma formation in mice. Am J Pathol 2004, 165:1211-1221

13. Yoneyama H, Harada A, Imai T, Baba M, Yoshie O, Zhang Y, Higashi $\mathrm{H}$, Murai M, Asakura $\mathrm{H}$, Matsushima K: Pivotal role of TARC, a CC chemokine, in bacteria-induced fulminant hepatic failure in mice. J Clin Invest 1998, 102:1933-1941

14. Hulseberg PD, Zozulya A, Chu HH, Triccas JA, Fabry Z, Sandor M: The same well-characterized T cell epitope SIINFEKL expressed in the context of a cytoplasmic or secreted protein in BCG induces different CD8 + T cell responses. Immunol Lett 2010, 130:36-42

15. Chensue SW, Warmington K, Ruth J, Lincoln P, Kuo MC, Kunkel SL: Cytokine responses during mycobacterial and schistosomal antigeninduced pulmonary granuloma formation: production of Th1 and Th2 cytokines and relative contribution of tumor necrosis factor. Am J Pathol 1994, 145:1105-1113
16. Qiu B, Frait KA, Reich F, Komuniecki E, Chensue SW: Chemokine expression dynamics in mycobacterial (type-1) and schistosomal (type-2) antigen-elicited pulmonary granuloma formation. Am J Pathol 2001, 158:1503-1515

17. Chiu BC, Shang XZ, Stolberg VR, Komuniecki E, Chensue SW: Population analysis of $C D 4+T$ cell chemokine receptor transcript expression during in vivo type-1 (mycobacterial) and type-2 (schistosomal) immune responses. J Leuk Biol 2002, 72:363-372

18. Chiu BC, Chensue SW: Chemokine responses in schistosomal antigen-elicited granuloma formation. Parasite Immunol 2002, 24:285294

19. Chiu BC, Stolberg VR, Freeman CM, Chensue SW: Mononuclear phagocyte-derived interleukin-10 suppresses the innate pulmonary granuloma cytokine response in aged mice. Am J Pathol 2007, 171 $829-837$

20. Chiu BC, Stolberg VR, Chensue SW: Mononuclear phagocyte-derived IL-10 suppresses the innate IL-12/IFN-gamma axis in lungchallenged aged mice. J Immunol 2008, 181:3156-3166

21. Chiu BC, Freeman CM, Stolberg VR, Hu JS, Zeibecoglou K, Lu B Gerard C, Charo IF, Lira SA, Chensue SW: Impaired lung dendritic cell activation in CCR2 knockout mice. Am J Pathol 2004, 165:11991209

22. Chiu BC, Freeman CM, Stolberg VR, Komuniecki E, Lincoln PM Kunkel SL, Chensue SW: Cytokine-chemokine networks in experimental mycobacterial and schistosomal lung granuloma formation. Am J Respir Cell Mol Biol 2003, 10:106-116

23. Wolf AJ, Desvignes L, Linas B, Banaiee N, Tamura T, Takatsu K, Ernst JD: Initiation of the adaptive immune response to Mycobacterium tuberculosis depends on antigen production in the local lymph node not the lungs. J Exp Med 2008, 205:105-115

24. Korbel DS, Schneider BE, Schaible UE: Innate immunity in tuberculosis: myths and truth. Microbes Infect 2008, 10:995-1004

25. Junqueira-Kipnis AP, Kipnis A, Jamieson A, Juarrero MG, Diefenbach A, Raulet DH, Turner J, Orme IM: NK cells respond to pulmonary infection with Mycobacterium tuberculosis, but play a minimal role in protection. J Immunol 2003, 171:6039-6045

26. Kawamura I: Protective immunity against Mycobacterium tuberculosis. Kekkaku 2006, 81:687-691

27. Emoto M, Emoto Y, Buchwalow IB, Kaufmann SH: Induction of IFNgamma-producing CD4+ natural killer T cells by Mycobacterium bovis bacillus Calmette Guerin. Eur J Immunol 1999, 29:650-659

28. Dieli F, Ivanyi J, Marsh P, Williams A, Naylor I, Sireci G, Caccamo N Di Sano C, Salerno A: Characterization of lung gamma delta T cells following intranasal infection with Mycobacterium bovis bacillus Calmette-Guerin. J Immunol 2003, 170:463-469

29. Maghazachi AA: G protein-coupled receptors in natural killer cells. J Leuk Biol 2003, 74:16-24

30. Meyer EH, Wurbel MA, Staton TL, Pichavant M, Kan MJ, Savage PB DeKruyff RH, Butcher EC, Campbell JJ, Umetsu DT: iNKT cells require CCR4 to localize to the airways and to induce airway hyperreactivity. J Immunol 2007, 179:4661-4671

31. Fenoglio D, Poggi A, Catellani S, Battaglia F, Ferrera A, Setti M Murdaca G, Zocchi MR: Vdelta1 T lymphocytes producing IFNgamma and IL-17 are expanded in HIV-1-infected patients and respond to Candida albicans. Blood 2009, 113:6611-6618

32. Adam C, King S, Allgeier T, Braumuller H, Luking C, Mysliwietz J, Kriegeskorte A, Busch DH, Rocken M, Mocikat R: DC-NK cell cross talk as a novel CD4+ T-cell-independent pathway for antitumor CTL induction. Blood 2005, 106:338-344

33. Andrew DP, Chang MS, McNinch J, Wathen ST, Rihanek M, Tseng J, Spellberg JP, Elias CG 3rd: STCP-1 (MDC) CC chemokine acts specifically on chronically activated Th2 lymphocytes and is produced by monocytes on stimulation with Th2 cytokines IL-4 and IL-13. J Immunol 1998, 161:5027-5038

34. Annunziato F, Galli G, Cosmi L, Romagnani P, Manetti R, Maggi E, Romagnani S: Molecules associated with human Th1 or Th2 cells. Eur Cytokine Network 1998, 9:12-16

35. Qiu L, Huang D, Chen CY, Wang R, Shen L, Shen Y, Hunt R, Estep J, Haynes BF, Jacobs WR Jr, Letvin N, Du G, Chen ZW: Severe tuberculosis induces unbalanced up-regulation of gene networks and overexpression of IL-22, MIP-1alpha, CCL27, IP-10, CCR4, CCR5, CXCR3 PD1, PDL2, IL-3, IFN-beta, TIM1, and TLR2 but low antigen-specific cellular responses. J Infect Dis 2008, 198:1514-1519 
36. Vulcano M, Albanesi C, Stoppacciaro A, Bagnati R, D'Amico G, Struyf S, Transidico P, Bonecchi R, Del Prete A, Allavena P, Ruco LP, Chiabrando C, Girolomoni G, Mantovani A, Sozzani S: Dendritic cells as a major source of macrophage-derived chemokine/CCL22 in vitro and in vivo. Eur J Immunol 2001, 31:812-822

37. Esser MT, Marchese RD, Kierstead LS, Tussey LG, Wang F, Chirmule N, Washabaugh MW: Memory T cells and vaccines. Vaccine 2003, 21:419-430

38. Jimenez-Martinez MC, Linares M, Baez R, Montano LF, MartinezCairo S, Gorocica P, Chavez R, Zenteno E, Lascurain R: Intracellular expression of interleukin-4 and interferon-gamma by a Mycobacterium tuberculosis antigen-stimulated CD4 + CD57+ T-cell subpopulation with memory phenotype in tuberculosis patients. Immunology 2004, 111:100-106

39. Katou F, Ohtani H, Nakayama T, Ono K, Matsushima K, Saaristo A Nagura $\mathrm{H}$, Yoshie O, Motegi K: Macrophage-derived chemokine (MDC/CCL22) and CCR4 are involved in the formation of T lympho- cyte-dendritic cell clusters in human inflamed skin and secondary lymphoid tissue. Am J Pathol 2001, 158:1263-1270

40. Kabelitz D, Wesch D: Features and functions of gamma delta $T$ lymphocytes: focus on chemokines and their receptors. Crit Rev Immunol 2003, 23:339-370

41. Casetti R, Martino A: The plasticity of gamma delta T cells: innate immunity, antigen presentation and new immunotherapy. Cell Mol Immunol 2008, 5:161-170

42. Khader SA, Cooper AM: IL-23 and IL-17 in tuberculosis. Cytokine 2008, 41:79-83

43. Inngjerdingen M, Damaj B, Maghazachi AA: Human NK cells express CC chemokine receptors 4 and 8 and respond to thymus and activation-regulated chemokine, macrophage-derived chemokine, and I-309. J Immunol 2000, 164:4048-4054

44. Sugawara I: Why does tuberculosis lead to specific inflammation? Nihon Hansenbyo Gakkai Zasshi 2009, 78:263-269 